\title{
Classical Foundationalism and Bergmann's Dilemma for Internalism
}

\author{
Ali Hasan \\ (Journal of Philosophical Research 36: 391-410, 2011)
}

\begin{abstract}
In Justification without Awareness (2006), Michael Bergmann presents a dilemma for internalism from which he claims there is "no escape": The awareness allegedly required for justification is either strong awareness, which involves conceiving of some justification-contributor as relevant to the truth of a belief, or weak awareness, which does not. Bergmann argues that the former leads to an infinite regress of justifiers, while the latter conflicts with the "clearest and most compelling" motivation for endorsing internalism, namely, that for a belief to be justified its truth must not be an accident from the subject's perspective. Bergmann's dilemma might initially seem to have the force of a knock-down argument against the classical foundationalist accounts he considers, if not against all forms of internalism. I argue, however, that the weak-awareness horn of Bergmann's dilemma is unsuccessful. Classical foundationalists can hold on to the main motivation for internalism and avoid a vicious regress of justifiers.
\end{abstract}

In Justification without Awareness (2006), Michael Bergmann presents a dilemma for internalism regarding epistemic justification from which he claims there is "no escape." The awareness allegedly required for justification is either "strong awareness," which involves the subject's conceiving of some justificationcontributor as relevant to the truth or justification of a belief, or "weak awareness," which does not. Bergmann argues that accepting a strong-awareness requirement leads to vicious regress problems and radical skepticism, while accepting a weakawareness requirement conflicts with, and hence deprives its proponents of, the "clearest and most compelling" motivation for endorsing internalism, namely, that for a belief to be justified its truth must not be an accident, stray hunch, or arbitrary conviction from the subject's perspective (2006: 12).

This resembles the Sellarsian dilemma for foundationalism, but it is, strictly speaking, a dilemma for internalism. ${ }^{1}$ It is worth noting, though, that the specific 
internalists Bergmann deploys his argument against-Fumerton (1995), McGrew (1995, 1999), BonJour (2003), and Fales (1996)—are all classical foundationalists. ${ }^{2}$ His focus on these classical foundationalists is motivated in part, I take it, by their explicit attention to the Sellarsian dilemma or similar regress problems in clarifying and defending their views. Bergmann claims that these internalists cannot avoid his own dilemma, whether or not their responses to the Sellarsian dilemma are successful (2006: 25). His dilemma is an improved attack that might initially seem to have the force of a knock-down argument against classical foundationalism, if not against all forms of internalism. I argue, however, that the weak-awareness horn of the dilemma is unsuccessful. Classical foundationalists can hold on to the main motivation for internalism and avoid a vicious regress of justifiers. ${ }^{3}$

\section{UNDESTANDING INTERNALISM AND WHY IT IS HELD}

Bergmann offers the following as the "canonical formulation" of a minimal internalist requirement. ${ }^{4}$

The Awareness Requirement: S's belief B is justified only if (i) there is something, $\mathrm{X}$, that contributes to the justification of $\mathrm{B}-\mathrm{e}$.g. evidence for $\mathrm{B}$ or a truth indicator for B or the satisfaction of some necessary condition of B's justification-and (ii) S is aware (or potentially aware) of X. (Bergmann 2006: 9)

Of course, many internalists will accept a stronger requirement, but Bergmann introduces a minimal version so that his dilemma has a very broad target. Note that what is required is awareness of some justification-contributors, broadly conceived, not all. Indeed, requiring awareness of all justification-contributors or conditions of justification leads to a vicious regress. ${ }^{5}$ Note also that according to the above requirement, S must be aware or potentially aware of some justification-contributor 
$\mathrm{X}$, where Bergmann takes potential awareness to involve the ability to become aware of $\mathrm{X}$ on the basis of reflection alone.

The main motivation for the awareness requirement is provided by reflection on examples like BonJour's famous case of Norman:

Norman, under certain conditions which usually obtain, is a completely reliable clairvoyant with respect to certain kinds of subject matter. He possesses no evidence or reasons of any kind for or against the general possibility of such a cognitive power or for or against the thesis that he possesses it. One day Norman comes to believe that the President is in New York City, though he has no evidence either for or against this belief. In fact, the belief is true and results from his clairvoyant power under circumstances in which it is completely reliable. (BonJour 1985: 41)

BonJour thinks it is intuitively obvious that Norman is not justified, and that this is because Norman fails to satisfy an awareness requirement; while the truth of his belief is not an accident from the standpoint of an external observer, "[f]rom his perspective it is an accident that the belief is true" (44). Bergmann summarizes the objection thus:

The Subject's Perspective Objection (SPO): If the subject holding a belief isn't aware of what the belief has going for it, then she isn't aware of how its status is any different from a stray hunch or an arbitrary conviction. From that we may conclude that from her perspective it is an accident that her belief is true. And that implies that it isn't a justified belief. (Bergmann 2006: 12)

The basic intuition to be wrung from such cases is that a belief that $p$ can be justified only if from the subject's perspective $p$ is true, likely, or more likely than its denial—only if, in other words, the subject is in some sense aware (implicitly or explicitly, actually or potentially) of the truth or likelihood of $p$. Of course, the proposition that the President is in New York is true from Norman's perspective in the purely psychological sense that he accepts its truth, but this does not make an epistemic difference, and Norman cannot go from being unjustified to being justified merely by becoming more confident in his belief. What Norman intuitively requires 
for his epistemic perspective on the proposition to improve is an awareness of a good reason or good evidence to think that the proposition is true. He probably also requires some sort of awareness of the relevance of the reason or evidence to the proposition's truth. It is because he lacks some such awareness of truth-conducive reasons that his perspective on the truth of this belief is no better than his perspective on a guess, stray hunch, or arbitrary conviction.

It is important not to build too much into the SPO insofar as it is motivated by cases like that of Norman, and Bergmann's statement of the SPO above is appropriately vague enough to leave open exactly what sort of awareness is required. That the subject must be aware of what the belief has going for it, that she must be aware of truth-conducive reasons or suitable justification-contributors, that the belief or proposition believed must be true from her perspective, etc., does not trivially entail that she must conceive of the belief as justified or as having some positive epistemic status, or indeed form any higher-order beliefs or judgments about that belief. ${ }^{6}$

\section{THE DILEMMA}

Bergmann distinguishes between "strong awareness," which involves conceiving of a justification-contributor that is the object of awareness as relevant in some way to the appropriateness, justification, or truth of the belief, and "weak awareness," which does not. Weak awareness may involve concepts, and may even involve conceiving of what is in fact a justification-contributor in various ways short of conceiving it as relevant to the truth or justification of the belief. The dilemma then proceeds as follows ${ }^{7}$ : 
1. An essential feature of internalism is that it makes a subject's actual or potential awareness of some justification-contributor a necessary condition for the justification of any belief held by that subject.

2. The awareness required by internalism is either strong awareness or weak awareness.

3. If the awareness required by internalism is strong awareness, then internalism has vicious regress problems leading to radical skepticism.

4. If the awareness required by internalism is weak awareness, then internalism is vulnerable to the SPO, in which case internalism loses its main motivation for imposing the awareness requirement.

5. If internalism leads to radical skepticism, then it should not be endorsed.

6. If internalism loses its main motivation for imposing the awareness requirement (i.e. avoiding the SPO), then it should not be endorsed.

7. Therefore, we should not endorse internalism.

In this paper I argue against the weak-awareness horn of the dilemma, premise 4 . I show that there are versions of internalism that accept only the weak awareness requirement but that are not vulnerable to the SPO, or at least that Bergmann has not shown otherwise. But first, let us briefly discuss Bergmann's defense of the strong-awareness horn of the dilemma, premise $3{ }^{8}$ This will help clarify what Bergmann is—and isn't—arguing for.

Why, according to Bergmann, does grabbing the strong-awareness horn lead to a vicious regress? If the strong-awareness requirement holds, then, for my belief B to be justified, I must be actually or potentially aware of some justificationcontributor $\mathrm{X}$, and actually or potentially conceive of $\mathrm{X}$ as relevant in some way to the truth or justification of B.

Suppose first that the awareness must be actual; I must actually be aware of $\mathrm{X}$, and actually conceive of $\mathrm{X}$ as relevant to the truth or justification of $\mathrm{B}$. Call the latter act of conceiving $\mathrm{C}$. This act $\mathrm{C}$ must also be justified or rational if the belief $\mathrm{B}$ that relies upon it is to be justified as well, even if $\mathrm{C}$ does not quite amount to a fullblown belief; as Bergmann points out, it would be odd to require justification for beliefs but not for the application of concepts (17). So, in order to be justified in 
applying $\mathrm{C}, \mathrm{I}$ must be aware of some contributor $\mathrm{X}^{*}$ to the justification of $\mathrm{C}$, and $\mathrm{I}$ must conceive of $\mathrm{X}^{*}$ as relevant to the correctness or justification of $\mathrm{C}$; that is, I must conceive of $X^{*}$ as relevant to the correctness or justification of conceiving $\mathrm{X}$ as relevant to the truth or justification of B. But again, this more complex act of conceiving — call it $\mathrm{C}^{*}$-must itself be justified. So I must be aware of some justification-contributor $\mathrm{X}^{* *}$, and conceive of $\mathrm{X}^{* *}$ as relevant to the correctness or justification of $\mathrm{C}^{*} \ldots$... This appears to lead to a regress of increasingly complex kinds of awareness. To be justified in any belief, I will have to be justified in an infinite number of beliefs or concept-applications that get more complicated the further we get in the regress.

What if we only require potential strong awareness? Things will hardly be better. I will not need to actually apply an infinite number of concepts of everincreasing complexity, but, for every concept I justifiedly apply, I will need to be able by reflection alone to apply each of an infinite number of concepts of ever-increasing complexity. This is an ability I do not have. ${ }^{9}$

Why should we not endorse an internalist view that leads to this sort of "radical skepticism" (premise 5)? After all, as Bergmann is well aware, internalists like Fumerton (1995:80-1) deny that skeptical implications of a theory of justification generally or automatically discredit it; even if we don't have good reasons for many of our beliefs, including beliefs regarding the external world, it doesn't follow that we don't need good reasons for our beliefs to be justified.

But it's another thing to think that, in order for any beliefs to be justified, the person holding it must have (or have the ability to form) an infinite number of beliefs of ever-increasing complexity. For in that sort of case, the problem isn't merely that the requirement has skeptical implications. It's also that the requirement just seems excessive, especially when put so bluntly. (Bergmann 2006: 22) 
Indeed, it seems to me that requiring an infinite chain or infinite tree of justifying beliefs is excessive enough, let alone one that has increasingly complex justifying beliefs the further back the regress goes. And the skeptical implication is nothing less than global: no belief, however simple or modest its content, could be justified in the internalist sense. Bergmann's challenge to the internalist is thus not that of avoiding skepticism regarding the external world-he is willing to set aside this concern for the sake of argument-but rather, that of avoiding vicious regress problems and global skeptical implications. Thus, in the present context, we cannot dismiss a version of internalism because it leads to the conclusion that we do not know (or justifiably believe) nearly as much as we thought. ${ }^{10}$ It will be important to keep this in mind below.

\section{THE WEAK-AWARENESS HORN}

Let us turn to Bergmann's defense of premise 4, the weak-awareness horn of the dilemma.

Suppose someone had an externalist view according to which it is necessary and sufficient for the justification of a belief that it be produced by a reliable belief-forming process. And suppose that Jack's belief B is produced by a belief-forming process token of a relevant process type that is, in fact, reliable (call this process token "RP"). Now imagine that a proponent of this reliabilist view sees that the SPO counts against her position and takes that to be a good objection. She decides to add to her account of justification the requirement of being [conceptually or nonconceptually] ${ }^{11}$ aware of the reliable process token in question.... (2006: 20)

Bergmann continues:

Will that pacify those who endorse SPO?

It shouldn't. For...Jack can be [conceptually or nonconceptually] aware of RP without conceiving of $\mathrm{RP}$ as relevant at all to the appropriateness of his belief. According to the SPO, if Jack does not conceive of RP as something relevant to the appropriateness of his belief then, even if $\mathrm{RP}$ is relevant to the 
appropriateness of his belief, it is an accident from Jack's perspective that his belief is true. (2006: 20)

Let's call this the case of "reliable Jack." So the idea is that since Jack does not conceive of RP as relevant to the appropriateness or truth of his belief, it remains an accident from his perspective that the belief is true.

Bergmann illustrates the problem by applying the dilemma to examples of introspective and perceptual belief (2006: 26-9). Consider the latter (we will turn to introspective belief below). Suppose that someone, let's call him "perceptual Jack," believes correctly that there is a large white ball before him (call this belief "B1"). Suppose that he is nonconceptually or conceptually (but not strongly) aware of a token of the type of visual experience a normal subject would have while looking at a white ball in standard conditions (call his visual experience "WB"), and that his belief is caused by WB. Bergmann says that "according to the proponents of the SPO, it's the case that from Jack's subjective perspective it is an accident that B1 is true" (2006: 27). So long as "Jack is only nonconceptually aware of WB" or in any case "applies only concepts other than ones like being indicative of B1's truth or being a contributor to B1's justification or being in some way relevant to the appropriateness of holding B1, B1's truth will, according to the SPO, be an accident from the subject's perspective" (2006: 27$).{ }^{12}$

It is important to understand the nature of Bergmann's argument. The SPO demands awareness of something that contributes to a belief's truth or justification. It does not explicitly require that this awareness be conceptual. So, while Bergmann's discussion of the above examples sometimes seems to suggest otherwise, the point is surely not that the SPO simply entails that a belief's truth is an accident from the perspective of a subject who does not conceive of some fact as 
relevant to its truth. Instead, we should understand Bergmann as providing some good examples which show that certain kinds of weak awareness will not capture the spirit of the SPO, examples that challenge the weak-awareness internalist to explain what form of awareness (short of strong awareness) could possibly satisfy the central intuition expressed by the SPO. Jack is aware of something (RP or WB) that is in some broad sense relevant to the truth of his belief (B or B1 respectively), and yet we still have the intuition that the truth is no better than accidental from his perspective. So, awareness of something that happens to be a cause or reliable producer of the belief is not sufficient for the belief's truth to be non-accidental from his perspective. What else does Jack need? One possibility would be to say that Jack needs strong awareness-for example, awareness that involves conceiving of $\mathrm{RP}$ or WB as a relevantly reliable or truth-conducive process-and it is perhaps difficult to see, at least initially, what else would work. This difficulty suggests that weak awareness is no better than no awareness.

Bergmann's examples thus raise a challenging question for internalists, namely, what kind of weak awareness could possibly make the relevant difference to the subject's perspective? In the remainder of this paper, I will answer this challenging question, showing that some forms of classical foundationalism avoid the SPO. By answering it, I will show that Bergmann was wrong to conclude that the SPO could be avoided only by strong awareness. In section IV, I defend Fumeton's view against the SPO. In section V, I defend McGrew's account of demonstratively formed beliefs against the SPO. Finally, in section VI, I offer an explanation for why some might be tempted to think that avoiding the SPO requires something like strong awareness. 


\section{ACQUAINTANCE WITH CORRESPONDENCE}

According to Fumerton, a belief that $p$ is basic or foundationally justified if and only if the subject is acquainted with some thought that $p$, acquainted with the fact $\mathrm{p}$, and acquainted with the correspondence between the thought that $p$ and the fact $\mathrm{p} \cdot{ }^{13} \mathrm{~A}$ fact is not to be regarded as propositional or linguistic; a fact is "a nonlinguistic complex that consists in an entity or entities exemplifying properties" (1995: 73). Facts are not true or false, they just are. Fumerton regards both acquaintance and correspondence as sui generis relations; acquaintance with correspondence or with anything else should not be understood as a conceptual act or an intentional relation. Acquaintance is a relation between the self or mind and some fact; to be acquainted with a fact is to have that fact itself directly before one's mind, and one cannot be acquainted with a fact that does not exist.

Bergmann interprets acquaintance with correspondence as a kind of "nonconceptual awareness," and says it is a little difficult to make sense of nonconceptual awareness of correspondence as opposed to nonconceptual awareness of something like pain, but grants it for sake of argument (2006: 30). But if he does grant it, then it seems that the addition of a nonconceptual awareness of correspondence can make the relevant kind of difference to the subject's perspective. Suppose that I am acquainted with my having a headache, acquainted with the thought that I have a headache, and acquainted with the correspondence between my thought and what it purports to describe, between the thought that I have a headache and my having a headache. Prima facie, it seems to just be overkill to now require that I also conceive of my headache as relevant to the truth or justification of my belief that I have a headache in order for the belief's truth to be non-accidental from my perspective. After all, if I am directly aware of the correspondence between 
a thought and a fact then everything constitutive of the thought's being true is there directly before my mind (Fumerton 1995: 74). Why require any more for the belief to be true from my perspective in a way that makes a difference to justification?

Bergmann objects to Fumerton's view, saying that Jack can be appeared to redly, believe that he is appeared to redly, and be nonconceptually aware of the correspondence between the belief and the experience

even if he has no idea that the relation of correspondence holds between these two items (again, this is because nonconceptual awareness is the sort of thing that can occur without the application of any concepts). Thus, Jack's belief...can satisfy Fumerton's requirements even if he conceives of his being appeared to redly as no more relevant to [his belief] than is the mild pain in his left knee. It is, therefore, exceedingly difficult to see how these direct acquaintances improve things from Jack's subjective perspective. (Bergmann 2006: 30)

Let's distinguish between two sorts of cases that Bergmann might have in mind: (a) Jack has some positive act of conceiving being appeared to redly as no more relevant to his belief than the mild pain; (b) Jack does not conceive of his being appeared to redly as relevant to his belief. Consider the latter first. If introspective Jack literally has no concept regarding the correspondence, or does not conceive of his being appeared to redly as relevant in any way to his belief that he is being appeared to redly, then, a fortiori, he does not conceive of it as more relevant than the mild pain in his left knee. But again, as Fumerton (1995: 74) points out, when everything constitutive of a thought's being true is directly before my mind, I have an ideal perspective on its truth, and it is unclear why any conceptualization of this correspondence is required.

What about interpretation (a)? It seems possible that Jack actually be directly aware of the correspondence between his being appeared to redly and the thought that he is appeared to redly, and yet conceive of his experience as an 
experience of mild pain. Or consider a possibility Bergmann raises in a nearby passage (2006: 28). It seems that Jack could (perhaps under the influence of a philosophically astute prankster) actually conceive of his experiences as epistemically irrelevant to his belief that he is being appeared to redly, or as no more relevant than the mild pain in his left knee. Doesn't this show that the nonconceptual awareness underlying cannot make a difference to the subject's epistemic perspective?

No. Whether the meta-belief that his experience is irrelevant to his firstorder belief is treated (i) as a defeater of his justification for the first-order belief, or (ii) as having very little or no effect on the epistemic status of his first-order belief, acquaintance with correspondence can still make a difference to Jack's epistemic perspective. Indeed, Bergmann's own discussion of defeaters suggests such replies, and the view he defends (or at least a natural extension of it) seems to support (i). ${ }^{14}$ Consider the following two "no-defeater" conditions on justification, the no-believeddefeater condition, and the no-justified-believed-defeater condition:

NBDC: S's belief B is justified only if S doesn't take B to be epistemically inappropriate (2006: 163).

NJBDC: S's belief B is justified only if S doesn't justifiedly take B to be epistemically inappropriate (or, more plausibly perhaps, only if S doesn't take $\mathrm{B}$ to be epistemically inappropriate with as much justification as $\mathrm{S}$ has for $\mathrm{B}$ ).

One can take a belief B to be epistemically inappropriate if one takes oneself to have good reasons or good evidence for the falsity of B, or one takes the source or ground on which the belief is based to be untrustworthy (Bergmann 2006: 163). Bergmann accepts NBDC and argues against the view that only beliefs that are to some degree justified can be defeaters. Suppose, for example, that you believe that you have hands on the basis of sensory experience, but you also come to believe that you are a 
brain-in-a-vat, and you believe that this makes your hand belief epistemically inappropriate. On Bergmann's view, any justification you might have had for the hand belief would be lost or defeated, whether or not the belief that you are a brainin-a-vat is justified (2006: 165). Others, myself included, might deny that an unjustified belief that you are a brain-in-a-vat can take away your justification for believing you have hands. There is some prima facie plausibility to each view, and I am not as confident as Bergmann is that NBDC is correct and that there is no good reason for the restriction. Fortunately, there is no need to settle this difficult issue here. Whether we accept NBDC or not, the acquaintance theorist can reply to the objection pushed in the above passage and continue to insist that acquaintance with correspondence can make a difference to the subject's epistemic perspective.

First, suppose we accept Bergmann's NBDC. Jack's belief that his experience is epistemically irrelevant to his first-order belief that he is appeared to redly seems to amount to a belief that the basis of his first-order belief is untrustworthy and so epistemically inappropriate. So, by NBDC, Jack's first-order belief that he is appeared to redly lacks justification. The acquaintance theorist can reply to Bergmann that Jack's first-order belief is unjustified not because acquaintance with correspondence is not a source of justification, but rather, because that justification is defeated. In other words, it simply doesn't follow from the fact that the proposition is not likely from Jack's perspective when he has the meta-belief that it wouldn't have been likely from Jack's perspective were he to lack the meta-beliefjust as it doesn't follow from the fact that E1 and E2 do not support P, that E1 doesn't support $\mathrm{P}$.

Alternatively, suppose Bergmann's NBDC is false. If Jack's meta-belief is not justified, or not as justified as the first-order belief, then it does seem plausible that 
the first-order belief is likely from his perspective. Again, when everything constitutive of a thought's being true is directly before my mind, I have an ideal perspective on its truth, and an unjustified or weakly justified conflicting meta-belief isn't going to change that. The account escapes the SPO.

\section{DEMONSTRATIVELY FORMED BELIEFS}

Bergmann also considers what he calls an infallibilist response to his dilemma that is inspired by the work of Timothy McGrew. ${ }^{15}$ McGrew defends a "minimum privileged access thesis," according to which "S has privileged access to his current mental states just in the sense that he can refer to them demonstratively, and no one else can do so" (1995: 89). To make the connection between demonstrative reference and demonstratively formed basic beliefs explicit, he introduces a "thesis of indexical embedding": "for any object of mental demonstrative reference it is possible to form a belief in which the indexical of reference stands in as a substantive" (90). We could express the belief roughly by saying that I am having this experience, or that I am appeared to thusly. McGrew claims that such basic or foundational beliefs are not only justified but guaranteed to be true for the simple reason that, if there were not some object for the demonstrative to refer to, the belief would be empty of content and hence not be a genuine belief at all.

Bergmann complains in passing that even if we grant that we have such infallible, demonstratively formed beliefs, they seem too meager a basis to ground beliefs about the external world (2006: 32-3). ${ }^{16}$ Of course, skepticism about the external world is not the issue he is focusing on; as we have seen, he is trying to saddle the internalist with the requirement of an infinite regress of justifiers, and he 
grants that one might be an internalist and a skeptic about the external world. So he sets this worry aside and raises the "more relevant worry that infallibilism...isn't an internalist view" (33). All that the version of infallibilism inspired by McGrew says is that a (contingent) foundational belief is justified only if it is impossible for $\mathrm{S}$ to believe that $p$ when $p$ is false, and this says nothing about S's awareness of anything.

However, McGrew's actual view suggests something like the following weakawareness requirement ${ }^{17}$ :

S's basic or foundational belief B (roughly expressible as "I am experiencing this" or "I am appeared to thusly") is justified only if (i) S is directly aware of or acquainted with some experience or feature of experience, and (ii) the demonstrative in S's belief B refers directly to the experience or experiential feature that is the object of awareness.

The subject is directly aware of or acquainted with some experience or experiential feature and believes of $i t$, the direct object of awareness, that it exists or is present. The object of direct awareness is built into the very content of the belief. The requirement seems to be a weak-awareness requirement that is not vulnerable to the SPO. If by virtue of attentive awareness to a particular experience or experiential feature, I can believe of the experience or feature itself that it is or exists, or that I am undergoing it, then the belief's truth is not accidental from my perspective. To put the point differently, for this kind of belief, to genuinely understand or grasp the content of the belief essentially involves an awareness of its truth-maker; there is really no distinction between grasping the content and grasping the truth-maker, and hence no sense in requiring some further awareness of a relation between them.

It is important to distinguish this view from the standard view of demonstratives. As I will explain in the remainder of this section, failure to do so 
can obscure the relevance of what McGrew calls demonstrative concepts to internalist justification, and make it easy to overlook connections to more recent work, by Gertler (2001), Chalmers (2003), and Nida-Rümelin (2004), on the content and epistemic significance of a special class of phenomenal concepts. I should stress that what follows is an oversimplified discussion of these views, one that inevitably ignores technical details and important qualifications. My main goal is just to highlight a central feature relevant to internalist justification that is shared by McGrew's demonstrative concepts and phenomenal concepts as the above authors understand them, a feature that demonstrative concepts as usually understood lack.

The standard view is that a demonstrative concept is something like an indexical. ${ }^{18}$ Consider indexical concepts like $I$, here, and now. The reference of these concepts is fixed by the context, by the speaker or thinker's identity, location, and time. On the standard view, the content of a token indexical concept is constituted by or essentially tied to the actual referent, much as the content of the concept water is constituted by or essentially tied to the actual referent in the environment (at least according to content-externalism about natural-kind concepts). ${ }^{19}$ The subject can apply these indexical concepts while having little or no awareness of the actual identity, location, and time, just as the subject can apply the concept water while having little or no awareness of the actual constitution of water. This content, being external to one's awareness or access, is not the sort of content relevant to internalist justification.

The standard view of demonstratives is similar. The actual referent of a token concept is taken to constitute or be essential to its content, but unlike the indexical concepts just discussed, the reference of a demonstrative is not fixed automatically by the speaker's identity, location and time; something else is needed 
to fix the reference. Consider, for example, the thought one might express by saying 'that is a tomato.' My identity, location, and time do not fix the referent of the demonstrative. Different views of the reference-fixing factor have been proposed, with the main suggestions being that reference is fixed by one or more of the following: a demonstration, understood as an act of pointing or gesturing or some similar behavior; an intention to point or refer to an object of a certain kind $^{20}$; or some appropriate causal or spatial relation (e.g., between the agent's pointing or utterance and some item in the environment). What is important for our purposes is that none of these views take the reference-fixing to be done purely by acquaintance or direct awareness. Indexicals and demonstratives are sometimes regarded as instruments or devices of "direct reference," but this is usually just taken to mean that the content of a token indexical or demonstrative just is the referent (or, perhaps, that such concepts lack content); it does not mean that the referent is an object of direct awareness. I may use tokens of the demonstrative 'that' in two separate contexts with the intention of picking out a physical object (e.g., "that is a tomato") and yet only succeed in picking out a physical object in one context because I am hallucinating in the other. On the standard view, these token concepts have different contents even if there is no difference in what I am directly aware of in the two cases. Thus, a demonstrative concept, as usually understood, picks out whatever one happens to be pointing to or gesturing at, whatever it is that one intends to point to or refer to, or whatever happens to stand in the appropriate causal or spatial relation to the agent. As Chalmers puts it, its content might be glossed roughly as "this, whatever it happens to be" (2003: 227). The subject can apply this concept and yet lack any awareness of the content or referent of the 
concept. This is not the sort of content that can make a difference to the subject's perspective, and hence be relevant to internalist justification.

McGrew's view and the standard view have at least one thing in common: the referent of a token demonstrative concept constitutes the content of the concept. But this similarity, together with the shared use of terms like 'demonstrative', 'reference', and 'direct', belies the important difference that, for McGrew, the reference is fixed by direct awareness, and not by acts of pointing or gesturing, by the subject's intentions to refer to a certain sort of thing, or by causal relations. There is no need to deny that there is a dimension of content that is contextual or external, or that demonstrative concepts as typically used in ordinary language, or in typical cases involving reference to objects of perception, behave more or less as the standard view has it. But McGrew could insist that there is another, epistemically more fundamental dimension of content fixed by direct awareness rather than an act of demonstration more broadly characterized..$^{21}$

McGrew is not alone in holding that experiential or phenomenal features can, by virtue of our direct awareness of them, constitute the content of a special class of concepts. Gertler (2001), Chalmers (2003), and Nida-Rümelin (2004) defend views very much in the same spirit, views that might be considered natural developments of McGrew's view. ${ }^{22}$ Gertler (2001) distinguishes between ordinary demonstratives, which typically involve an intention to pick out an entity that satisfies some description, and a pure demonstrative which picks out its referent solely by an act of demonstrative attention to a phenomenal property. Chalmers (2003) defends the view in some detail, providing an analysis of the two dimensions of content and the relations between them ${ }^{23}$, and motivating the need for what he calls a direct phenomenal concept, a concept constituted by a phenomenal quality. ${ }^{24}$ He notes that 
demonstratives are naturally used to express direct phenomenal concepts (e.g., "I am experiencing this quality"), and that there may be a sense in which a direct phenomenal concept is a "demonstrative" concept, but he avoids such a label at least in part because of the danger of confusing direct phenomenal concepts with demonstrative ones as usually understood (2003: 227). When it comes to such phenomenal concepts there is no "gap" left between what I am aware of or acquainted with and the phenomenal quality referred to by the concept, no "gap" of the sort that remains between what I am aware of and some perceptual object that I might refer to "directly" by pointing. If I attend to an object of direct awareness, e.g., an instance of phenomenal redness, I can believe of that instance that it is red, a direct phenomenal concept whose content is constituted by the phenomenal property attended to. For this kind of belief, there is no "gap" between grasping its content and grasping its truth-maker, and hence no sense in requiring any further awareness of a relation between them..$^{25}$

\section{THE APPEAL OF THE STRONG AWARENESS REQUIREMENT}

If what I have argued thus far is right, Bergmann fails to show that Fumerton and McGrew's weak-awareness accounts are vulnerable to the SPO. But how might a weak-awareness internalist explain the temptation to think that avoiding the SPO requires something like strong awareness? Various factors might be at work here, but a look at some parts of BonJour's influential discussion of Norman suggests one plausible explanation of this temptation, an explanation that is very similar to the "error theory" Bergmann himself provides to explain the appeal of higher-level requirements on justification. ${ }^{26}$ Suppose that Norman does not 
believe that he has any clairvoyant power; he does not believe that his belief the

President is in New York is reliable. BonJour says that

...if this specification is added to the case, it becomes quite difficult to understand what Norman himself thinks is going on. From his standpoint, there is apparently no way in which he could know the President's whereabouts. Why then does he continue to maintain the belief that the President is in New York City? Why isn't the mere fact that there is no way, as far as he knows, for him to have obtained this information a sufficient reason for classifying his belief as an unfounded hunch and ceasing to accept it? And if Norman does not do this, isn't he thereby epistemically irrational and irresponsible?

Thus, I submit, Norman's acceptance of the belief about the President's whereabouts is epistemically irrational and irresponsible, and thereby unjustified.... Part of one's epistemic duty is to reflect critically upon one's beliefs, and such critical reflection precludes believing things to which one has, to one's knowledge, no reliable means of epistemic access. (BonJour 1985: 42; cited in Bergmann 2005: 429-30)

This talk of one's "epistemic responsibility" or "epistemic duty to reflect critically upon one's beliefs" might lead one to accept the strong awareness requirement by something like the following reasoning. A belief is epistemically justified only if it is held in an epistemically responsible way. Norman's belief appears to be epistemically irresponsible, for he does not undertake the minimum critical reflection on this belief that being epistemically responsible requires. To be epistemically responsible, Norman must reflect on his belief and consider whether he is aware of anything relevant in any way to the truth or appropriateness of his belief that the President is in New York, anything that could provide a reason to think that the President is indeed in New York. If he considers this question and is proceeding in an epistemically responsible way, he will take some attitude or other relative to some proposition to the effect that he is aware of a good reason to think that the President is in New York; he will come to believe, disbelieve, or withhold belief from that proposition. If he comes to disbelieve or withhold belief from this 
proposition and yet continues to believe that the President is in New York, then the latter belief is not responsibly held. Therefore, in order to be epistemically justified in believing that the President is in New York, Norman must believe that he is aware of something that provides a good reason to think that the President is indeed in New York. This suggests that, more generally, S is epistemically justified in believing that $p$ only if $\mathrm{S}$ believes that $\mathrm{S}$ is aware of something that is relevant to the truth or appropriateness of believing that $p$.

Something like this reasoning helps explain the tendency to think that avoiding the SPO requires strong awareness. However, as an explicit bit of reasoning it is unimpressive. First, there is the controversial claim that epistemic justification requires epistemic responsibility (or perhaps that it requires some sort of diachronic or methodological rationality having to do with how one ought to change one's beliefs over time in light of one's apparent evidence). At the time of his initial discussion of the Norman case, BonJour explicitly held that the concept of epistemic justification is deontological at its core, having to do with epistemic responsibility (1985: 8). But most if not all classical foundationalists (and many other epistemologists), including BonJour himself, deny this (BonJour 2001; Fumerton 1995: 8-20).

Second, even granting that Norman cannot be epistemically responsible or epistemically justified in his belief that the President is in New York unless he holds some higher-level attitude about this belief, it does not follow that no belief can be justified unless the subject also has a justified higher-level attitude about it. That Norman lacks any higher-level attitude about the reliability of his belief makes it very difficult to see how he could be justified, especially given how isolated this belief is from any other perceptual beliefs. But this leaves entirely open the 
possibility that there are some facts (e.g., facts about our own conscious mental states) of which we can be directly aware and on the basis of which we can form some responsible or justified beliefs. When we focus on cases like that of Norman it is easy to ignore this possibility and thereby by misled to generalize from the Norman case and hold that, for any belief, that belief is justified only if one conceives of some object of awareness as relevant in some way to its truth or reliability. I'm not saying, of course, that internalists who are inclined to accept the strongawareness requirement rely explicitly on anything like the above reasoning, but it can explain how some might be led to accept the strong awareness requirement by reflection on cases like that of Norman.

\section{CONCLUSION}

What should we say about reliable Jack and perceptual Jack? What kind of grasp of the relevance of their evidence to the truth of their respective beliefs would yield justification? The classical internalist foundationalists Bergmann is engaging would insist that what we need here are principles of inductive or abductive reasoning that, at a fundamental level, will have to be justifiable a priori. While there's a strong intuitive pull to the idea that we can be directly aware of simple entailment relations, just as Fumerton claims we can be directly aware of correspondence relations, matters are much more complicated here. ${ }^{27}$ But, as we have seen, Bergmann grants that one may be an internalist and a skeptic; it may be that we need good reasons to be justified in our beliefs, and that for many of our beliefs, we lack the good reasons we need. So, even if we don't have the kind of a priori grasp of connections we would need to be justified in beliefs about the external 
world, none of this would show that internalists cannot use cases like Norman to support an awareness requirement on justification.

I have shown that classical foundationalists can hold on to the main motivation for internalism without being saddled with an infinite regress of justifiers. Appealing to the kinds of awareness I have discussed will no doubt strike some as ad hoc, but I don't think it is. These moves account for the intuitions in the Norman case, end the regress of justification, and preserve an intuitive distinction between a belief's being based upon or grounded in good evidence and its being merely caused by something that could in principle serve as good evidence. And, pre-theoretically, the claim that we can be internally justified in accepting at least some beliefs is very plausible. ${ }^{28}$

\section{BIBLIOGRAPHY}

Bergmann, Michael. 2005. "Higher-Level Requirements and Defeaters." Philosophical Quarterly 55: 419-36.

-----2006. Justification without Awareness. Oxford: Oxford University Press. BonJour, Laurence. 1978. "Can Empirical Knowledge Have a Foundation?" American Philosophical Quarterly 15: 1-13.

----1985. The Structure of Empirical Knowledge. Cambridge, MA: Harvard University Press.

----1995. In Defense of Pure Reason. Cambridge, MA: Cambridge University Press.

----2001. "The Indispensability of Internalism." Philosophical Topics 29: 47-65.

----2003. "A Version of Internalist Foundationalism.” In L. BonJour and E. Sosa, Epistemic Justification: Internalism vs. Externalism, Foundations vs. Virtues. Malden, MA: Blackwell.

Braun, David. 2007. "Indexicals." The Stanford Encyclopedia of Philosophy (Winter 2007 Edition), Edward N. Zalta (ed.), URL = $<$ http://plato.stanford.edu/archives/win2007/entries/indexicals/>.

Chalmers, David. 2002. "The Components of Content." In Chalmers (ed.), The Philosophy of Mind: Classical and Contemporary Readings. New York: Oxford University Press.

----2003. "The Content and Epistemology of Phenomenal Belief." In Q. Smith and A. Jokic (eds.), Consciousness: New Philosophical Essays. Oxford: Oxford University Press.

Crisp, Thomas. 2010. “A Dilemma for Internalism?” Synthese 144 (3). 
Fales, Evan. 1996. A Defense of the Given. Lanham, MD: Rowman \& Littlefield. Fumerton, Richard. 1995. Metaepistemology and Skepticism. Lanham, MD: Rowman \& Littlefield.

Gertler, Brie. 2001. "Introspecting Mental States." Philosophy and Phenomenological Research 63: 305-328.

Huemer, Michael. 2001. Skepticism and the Veil of Perception. Lanham, MD: Rowman \& Littlefiled.

----2007. "Compassionate Phenomenal Conservatism.” Philosophy and Phenomenological Research, 74 (1): 30-55.

Jackson, Frank. 1982. "Epiphenomenal Qualia." Philosophical Quarterly 32: 127-36. Kaplan, David. 1989. "Demonstratives." In Almog, Perry, and Wettstein (eds.), Themes from Kaplan. New York: Oxford University Press.

McGrew, Timothy. 1995. The Foundations of Knowledge. Lanham, MD: Littlefield Adams Books.

----1999. “A Defense of Classical Foundationalism.” In L. Pojman (ed.), The Theory of Knowledge: Classical and Contemporary Readings (2nd ed.). Belmont, CA: Wadsworth.

Matheson, Jonathan, and Rogers, Jason. Forthcoming. "Bergmann's Dilemma: Exit Strategies for Internalists." Philosophical Studies.

Nida-Rümelin, Martine. 2004. "What Mary Couldn't Know: Belief about Phenomenal States." In Ludlow, Nagasawa, and Stoljar (eds.), There's Something About Mary. Cambridge, MA: MIT.

Pryor, James. 2000. "The Skeptic and the Dogmatist." Nous 34 (4): 517-549.

----2004. "What's Wrong with Moore's Argument?" Philosophical Issues 14: 349-378.

Russell, Bertrand. 1912. The Problems of Philosophy. London: Williams and Norgate.

Sellars, Wilfrid. 1963. "Empiricism and the Philosophy of Mind.” In Science, Perception and Reality. London: Routledge.

----1975. "The Structure of Knowledge." In H. N. Castaneda (ed.), Action, Knowledge, and Reality. Indianapolis: Bobbs-Merrill.

\footnotetext{
${ }^{1}$ The Sellarsian dilemma is named after Wilfrid Sellars, in whose work it appears in at least a roughly similar form (see Sellars 1963, Part I; 1975). BonJour (1978, 1985, and with a response in 2003) presents the dilemma in a clearer, more commonly repeated form. The Sellarsian dilemma goes roughly as follows. The ultimate foundations of justification are either propositional/conceptual, or they are not. If they are

${ }^{2}$ These are all classical foundationalists not in the sense that they require infallible or incorrigible foundational beliefs (though at least one of them does), but in the sense that they are committed to some version of the doctrine of the given - roughly, the idea that basic empirical beliefs can be justified on the basis of a direct or immediate awareness of mental states and their properties. The Sellarsian dilemma (see n. 1) is often directed at versions of classical foundationalism, with some form of direct or immediate awareness or acquaintance taking the place of the "foundations" in the dilemma.

${ }^{3}$ Crisp (2010) and Matheson and Rogers (forthcoming) also defend internalism against Bergmann's dilemma. Crisp argues against the strong-awareness horn of the dilemma, while I argue against the weakawareness horn here. Matheson and Rogers argue against both horns. They say that they find it plausible that a version of classical foundationalism or acquaintance-theory can escape the dilemma. However, they (and Crisp) focus primarily on showing that some version of the view that beliefs can be justified by "seemings" or "seeming-states" (propositional states distinct from belief) can escape the dilemma. (For a defense of such a view, see Huemer 2001 and 2007. I find the appeal to seemings in response to the weakawareness horn of the dilemma problematic. I will not argue for this in detail here, but see $\mathrm{n} .12$ below for a sketch of the argument I have in mind). My primary aim, on the other hand, is to defend some versions of classical foundationalism against the dilemma. However, proponents of non-classical views might find my
} 
reply to Bergmann's dilemma useful in considering how to strengthen their replies to the weak-awareness horn of the dilemma.

${ }^{4}$ This is a requirement for awareness-internalism as opposed to mentalism. Mentalism is, roughly, the view that justification is essentially a function of, or supervenes on, the subject's mental states. Bergmann argues against awareness-internalism in the first two chapters of his book, and then moves on to argue against mentalism in the third chapter. I want to defend awareness-internalism against Bergmann's dilemma, and will say nothing about mentalism.

${ }^{5}$ Let $\mathrm{X}$ be a justification-contributor of a belief of mine. Since I must be aware of all justificationcontributors, I must be aware of $X$. It follows that awareness of $X$ is itself a justification-contributor for my belief - call it $X^{*}$. But then, since $X^{*}$ is a justification-contributor, I must also be aware of it, and so awareness of $X^{*}$ is also a justification-contributor - call it $X^{* *}$. So, I must also be aware of $X^{* *} \ldots$ This clearly leads to an infinite regress. See Bergmann 2006: 9-10, n. 13, and Fumerton 1995: 81.

${ }^{6}$ In his initial discussion of the Norman case, BonJour suggests that "the rationality or justifiability" of the belief "should be judged from Norman's own perspective" (1985: 42-4; see also section VI below). It is not obvious that justification generally requires some epistemic or higher-order judgment or belief, and many of today's internalists, including BonJour himself, would deny it. In more recent work also cited by Bergmann, BonJour expresses the intuition a bit more cautiously (BonJour 2003: 27-32).

${ }^{7}$ The argument here is just as Bergmann presents it (13-14), except that he combines premises 5 and 6 into a single premise.

${ }^{8}$ Crisp 2010 and Matheson and Rogers (forthcoming) argue against the strong-awareness horn of the dilemma.

${ }^{9}$ For Bergmann's more detailed defense of premise 3, see section 3.2, 14-8.

${ }^{10}$ Thanks to an anonymous referee of the journal for suggesting that I make this more explicit.

${ }^{11}$ Bergmann actually treats nonconceptual and conceptual weak awareness separately, but applies the very same reasoning for both.

${ }^{12}$ Can the fact that it seems or appears (a propositional attitude distinct from belief) to Jack that there is a white ball in the room make a difference to his justification? On some views, such as Pryor's dogmatism $(2000,2004)$ and Huemer's phenomenal conservatism $(2001,2007)$, its seeming or appearing to $S$ that $p$ provides some degree of prima facie or defeasible justification for the belief that $\mathrm{p}$. If we make explicit that it does seem to Jack that there is a white ball in the room, a dogmatist or conservative might find it intuitive to say that the belief is true from Jack's perspective. Indeed, Matheson and Rogers (forthcoming) argue against Bergmann that seemings can make a difference to the subject's perspective. Bergmann (2006) doesn't explicitly discuss this sort of view, though I am happy to grant that it is vulnerable to the SPO.

While I cannot argue for this in detail here, I find the appeal to seemings in response to the weakawareness horn of the dilemma problematic. When we add to the Norman case that it seems to Norman that the president is in NY - the proposition seems to be true or strikes Norman as true-and leave everything else in the case as is, this intuitively makes no difference to Norman's epistemic perspective. Matheson and Rogers attempt to address this sort of concerns in a long footnote (forthcoming: $\mathrm{n}$. 22). They say that while in the original case Norman has nothing other than the belief itself that might make a difference to his perspective on the belief, in this case there is something else - the seeming itself-that makes a difference. But what is it that is in my perspective when it seems to me that $p$ ? Is it just the proposition $p$ (or perhaps the proposition $p$ is true) that is in the subject's perspective? But if this is all, then it is not clear why this makes an epistemic difference, whereas merely thinking or consciously believing that $p$ (or that $p$ is true) does not. In response, one might claim that a seeming that $p$ involves a distinctive phenomenology, a felt or conscious "pull" or "impulsion" towards the truth of $p$ (Matheson and Rogers: n. 22). For it to seem to me that $p$ is for me to be aware of or have within consciousness the assertive, striking-me-as-true character of my attitude towards $p$. This idea might be fleshed out in different ways. We might hold that having a seeming that $p$ involves a direct awareness of the distinctive assertive character of the attitude. Alternatively, we might hold that whenever $\mathrm{S}$ has a first-order seeming that $p$, it also seems to $\mathrm{S}$ that it seems to her that $p$, either by S's having a distinct second-order seeming state or a second-order representation as part of the same token state. Whatever the particular proposal, the following familiar problem arises. Suppose that it seems to me that there is a red table here, and so I am in some way aware of its seeming to me that there is a red table here. Does that improve my perspective on the truth of the proposition? Once we bring the fact that I have thus-and-such seemings into my perspective, perhaps these can provide evidence, but the evidence cuts both ways: various skeptical hypotheses become relevant, and I 
need some reason to think that the actual truth of a proposition accounts for its seeming to be true better than anything else does. I need some reason to think that the hypothesis that there is a table here accounts for its seeming to me that there is a table here, and that it does so better than the hypothesis that I am hallucinating a table. I need some reason to think that the table's being red accounts for its seeming to me to be red, and does so better than the hypothesis that it is a white table illuminated by red lights. Unless I have some such reason, it is difficult to see why the seeming, of which I am aware, makes any difference to my perspective on the belief's truth.

${ }^{13}$ Fumerton qualifies the analysis to allow a false belief to be foundationally justified, in some circumstances, by acquaintance with a fact very similar to one that would correspond to the false proposition believed. The matter of whether and how we should accommodate fallible foundations, while important, introduces complications and difficulties that I have no room to discuss here.

${ }^{14}$ I am grateful to an anonymous referee of the journal for pointing out that Bergmann's own discussion of defeaters might be relevant here.

${ }^{15}$ McGrew accepts an infallibility or incorrigibility thesis only for foundational beliefs. For simplicity, Bergmann considers a view that accepts the infallibility thesis for all justified beliefs. See Bergmann 2006 : 32, n. 7.

${ }^{16}$ What Bergmann actually says is that "it is doubtful in the extreme that we can, on the meager basis of such beliefs together with infallible a priori beliefs in necessary truths, arrive infallibly at any conclusions about the external world" (33, my emphasis). McGrew accepts infallibility only for foundational beliefs, though Bergmann ignores that "wrinkle" for simplicity (32, n. 7).

${ }^{17}$ Bergmann does consider a different weak-awareness internalist version of infallibilism, one according to which justified belief requires nonconceptual awareness of its being impossible that the belief be false, and he argues in a similar fashion as he did against Fumerton that the view is vulnerable to the SPO.

${ }^{18}$ For a useful introduction to Kaplan's 1989 work on demonstratives and its influence, see Braun 2007.

${ }^{19}$ On the standard view, indexicals (and natural-kind concepts like water) are "rigid designators": roughly, they pick out the same thing — whatever the referent happens to be in the actual world — in all possible counterfactual worlds.

${ }^{20}$ Even the reference of indexicals like here and now is often fixed by the speaker's intentions. In saying that "we have beer here" I may intend to refer to a house, a city, a state, or a continent. In this respect, some indexicals are more like demonstratives than pure indexicals like $I$.

${ }^{21}$ For example, BonJour (1995: 170-4) grants that indexicals and natural-kind concepts like water have a content that is external or contextual, but denies that there is any clear reason to think that there is no content in the vicinity that is internal or more clearly relevant to internalist justification.

${ }^{22}$ Chalmers is more explicit about the connections to classical foundationalism. See his discussion of acquaintance and justification in 2003: section 4.

${ }^{23}$ For a useful, brief introduction to the two-dimensional semantic framework, see Chalmers 2003: 268-71.

${ }^{24}$ Chalmers and Nida-Rümelin argue that it is difficult to make sense of the epistemic progress of subjects like Jackson's (1982) Mary unless we accept that there is a core phenomenal concept whose content is constituted by an underlying phenomenal or experiential quality. After being confined to a black-and-white environment for all her life, Mary is allowed to experience color for the first time. Intuitively, Mary will learn something new; she will learn what it is like to experience red. And it doesn't seem that she could have arrived at this knowledge of what it is like to experience red by having some descriptive or comparative knowledge regarding phenomenal redness (e.g., conceiving it as the phenomenal quality normally produced in such-and-such subjects in such-and-such conditions), or by picking out the phenomenal quality indexically.

${ }^{25}$ Direct phenomenal concepts last only as long as the experiences that constitute their contents. But subjects might retain knowledge of what an experience is like even after the experience is long gone, by acquiring what Chalmers calls a standing phenomenal concept. Standing phenomenal concepts are still very much like direct phenomenal concepts, and not like concepts that depend on some further description or some act of demonstration. While Chalmers does not say exactly what determines the content of such concepts, he finds it "plausible that their content is determined by some combination of (1) non-sensory phenomenal states of a cognitive sort, which bear a relevant relation to the original phenomenal quality in questions - e.g., a faint Humean phenomenal 'idea' that is relevantly related to the original 'impression'; (2) dispositions to have such states; and (3) dispositions to recognize instances of the phenomenal quality in question" (2003: 239). 


\footnotetext{
${ }^{26}$ See Bergmann's "Defeaters and the Higher-Level Requirement" (2005). Bergmann notes the tendency on the part of some internalists (e.g., BonJour, in the passage below) to think that we ought to reflect critically on our beliefs, and hence, that we ought to take up some doxastic attitudes regarding the epistemic appropriateness or reliability of our beliefs (430). I have benefited from his discussion in putting together the similar explanation offered here. There are, however, some differences, at least in emphasis. I emphasize that the tendency to think that justification or rationality requires critical reflection is encouraged by a focus on deontological notions like epistemic responsibility and epistemic duty. I also add that focusing on cases like Norman's belief that the President is in New York, the justification of which is exceedingly difficult to make sense of in the absence of some belief regarding the appropriateness or reliability of such beliefs, might encourage a hasty generalization to the claim that $n o$ belief whatsoever is justified in the absence of a belief regarding its appropriateness or reliability. I am grateful to an anonymous referee of this journal for directing my attention to Bergmann's paper and its potential relevance in this context.

${ }^{27}$ Fumerton (1995: 218) admits that he cannot quite bring himself to believe that he is directly acquainted with probability relations, and it's not obvious that there's a coherent notion of self-evident probability relations. Perhaps some interpretation of probability as a relation between propositions (e.g., a Keynesian conception of probability), and so as something like an entailment relation, can help. But these are difficult matters that I cannot go into here.

${ }^{28}$ Thanks to Larry BonJour, Richard Fumerton, Michael Bergmann, Evan Fales, Ian Schnee, Ian Evans, and an anonymous referee of the journal for helpful comments on earlier drafts. Thanks also to David Alexander, Ann Baker, Ben Almassi, Brandon Morgan-Olsen, Sam Taylor, Travis Dickinson, Brett Coppenger, Ian MacMillan, and John DePoe for helpful discussion.
} 